\title{
Exploration and Innovation of Modular Teaching Practice Mode of Tourism Craft Design Course
}

\author{
Yujuan Li \\ Yantai Nanshan University \\ Longkou, China
}

\begin{abstract}
The establishment of the tourism crafts design specialty is a new-developing specialty that has emerged along with the development of the tourism industry. It has been constantly exploring the progress of talent training models. Modular teaching practice mode is to explore and innovate the training mode in order to achieve the training goal based on the talent demand of the professional market. The implementation of the modular teaching practice mode is conducive to the construction of an application-centric teaching system, and it is an attempt to train professionals with practical ability and market integration, which has a certain reference function for the development of this and related majors.
\end{abstract}

Keywords—tourism craft design; modular teaching; teaching practice mode

\section{INTRODUCTION}

With the rapid development of China's tourism industry, the specialty of tourism handicraft design has emerged and gradually developed. It is an emerging specialty with distinct professional characteristics and broad employment prospects. The specialty of tourism handicraft design is an interdisciplinary comprehensive discipline, and the goal of talent training is compound talents with high practical skills in tourism handicraft planning, design, research, and development.

However, most of the domestic vocational colleges and comprehensive colleges and universities have specialized in the teaching of professional theoretical knowledge in the training mode of tourism crafts design talents. Practical education is mostly in the form and out of touch with market demand. For example, in the study of art appreciation, composition, and materials of professional basic courses, it neglects the cultivation of students' thinking in the application of later professional skills courses, and doesn't translate theoretical knowledge into the support of design, making students feel that the courses are boring and difficult to understand and make them feel that what they've learned is useless, which discourages their enthusiasm for learning. In terms of skill training, although the institutions now focus on the development of school-enterprise cooperation and present diversification in the number and form of cooperation, there are very few units that can effectively achieve effective cooperation. Due to the limitation of time and conditions, students can't get effective professional skills training and practice, which greatly affects the effect of professional ability training and is in an awkward position.

Although colleges and universities now advocate taking students as the mainstay, teachers as guides and service providers, they have had little effect. Most of the current teaching methods still follow the traditional education model, with teachers as the center of education, and students' autonomy is not fully valued and developed. Teachers rely on the syllabus, teach according to the prescribed order, and mainly use cramming method of teaching. Students have not become the main body of the classroom and have not formed a complete understanding of the curriculum, lack of understanding and application.

To sum up, the education model of tourism crafts design specialty is generally biased to the traditional. It is difficult to meet the market demand and achieve the training goal of applied professional education. It is imperative to change the teaching model. In order to reform the education training mode, it is necessary to firstly change the thinking mode of educators, improve the quality of teachers, and highlight the students' main body status, so as to truly realize the progress of education mode and achieve good reform results.

\section{BASIS FOR CUltivation OF TOURISM CRAFT DESIGN TALENTS}

\section{A. Market-oriented and Clear Training Goals}

The industrial structure of different industries is different, and the demand for industry talents is also very different. Therefore, when cultivating design talents for tourism crafts, it is needed to formulate clear and satisfactory training goals according to the overall guidance of market demand, so that professional advantages can be brought into full play to meet the requirements of market development.

First, efforts should be paid to understand the market dynamics in real time, conduct in-depth market research, grasp the current status and development trends of the tourism industry, locate and cultivate the professional orientation of tourism crafts professionals, carry out a professional analysis of the training goals, and determine the professional training goals; second, it is necessary to establish a teaching system suitable for the needs of the tourism crafts industry, keep pace with the times, adjust in a timely manner, update the teaching content in real time, 
advantages are mainly reflected in: on the one hand, the concentration of time can effectively ensure that the associated multilevel knowledge can be quickly integrated and connected in a short time; on the other hand, it can minimize the time span up to the hilt and increase the amount of knowledge information transmission; Thirdly, it is beneficial for students to quickly transform the theoretical knowledge they have learned into practical skills, enrich practical experience, and strengthen their ability to understand and apply theoretical knowledge.

For example, in the past, the problems of "single subject teaching" such as curriculum inconsistency and inversion not only increased the learning burden of students, reduced learning efficiency, but also greatly discouraged students' interest in learning and self-confidence. As a result, the theoretical knowledge of students is out of touch with the practical ability, and can't meet the job demands.

In the implementation of the modular teaching mode of the tourism crafts design specialty, the teaching arrangement is set according to the optimization principle, which has a positive impact on the effect and efficiency of students. Modular teaching has changed the traditional independent and decentralized curriculum setting mode, and the related courses are centralized for a period of time for teachers to carry out theoretical and practical teaching. Subject modules are designed according to the actual time period or content, and each subject contains corresponding professional knowledge and practical requirements within the course time, so that students can fully learn the related overall knowledge content within a period of time and master relevant basic knowledge, professional knowledge and practical skills.

\section{B. Segmented Modular Teaching}

Segmented modular teaching fully reflects the competency-based vocational education concept. On the one hand, in terms of teaching content, methods, and assessment standards, it is closely integrated with industry needs and industry assessment standards, gets rid of the traditional classroom teaching model and highlights the characteristics of vocational education. It shortens the distance between teachers and onsite positions, and improves the ability to combine theory with practice. Performing nearfield skills tests on students also encourages teachers to master and learn onsite skills and apply them to teaching; on the other hand, segmented teaching also gives teachers more time to go to the site to take part-time job and engage in advanced studies, further improving professional skills.

In the segmented modular teaching process, the smallclass teaching is adopted to facilitate communication between students and teachers, which strengthens the management and guidance of students by teachers; the use of double-professionally-titled teachers with relatively rich professional experience and employment guidance knowledge has a direct impact on the effectiveness of modular teaching; the student's job internship or job simulation allows students to understand their own deficiencies and specific requirements of the job during the
In recent years, efforts are paid to adjust and innovate the curriculum, update the teaching content, innovate teaching methods, and try to modularize curriculum settings. Its 


\section{A. Theme Case Discussion and Practice Method}

From market research, to the positioning of crafts themes, to sample image and material design, and finally to physical production and sales, market sales feedback surveys, the entire process completely simulates the crafts design promotion process of crafts companies. Team members are responsible for the main responsible persons of different links, participate in the design and promotion of the product together, and train students' communication ability, design ability and teamwork ability. with the level of student mastery. It should be based on not superficial, truly starting from the post, starting from practice, and training the students' comprehensive ability.

The theoretical knowledge module should be based on the learning goals, and select people who have strong theoretical knowledge and a certain amount of practical knowledge, so that the theoretical course learning and training can achieve good results.

Students' practical training module, in addition to skills training, should also focus on the training of innovative thinking, guide students to flexibly deal with problems in future positions, and improve student autonomy and selfconfidence.

The job simulation internship part should aim at the different abilities and interests of students, and focus on rationally arranging training so that people meet the job requirements, and are more suitable for job requirements, and achieve the goal requirements of talent training.

The form of off-campus internship bases should be diversified to provide more opportunities and guarantees for on the job internships.

For modular teaching to achieve a good training effect, double-professionally-titled teachers with theoretical knowledge and practical ability are essential. At the same time as completing the training of students 'practical ability, teachers' learning and training in the enterprise must also be on the agenda to make the teacher really understand the enterprise and know how to adapt to the needs of the enterprise, so that the students can be trained in a targeted manner.

\section{MOdUlar TEACHING FOR TOURISM CRAFTS DESIGN MAJOR — POST SimUlation PRACTICE MODUlE}

The most important goal of the modular teaching of tourism crafts design major is to realize the cultivation of students' practical ability, so that the students in the school have an understanding of the specific requirements of future jobs, and master the theoretical knowledge and practical skills required by actual jobs. The post simulation internship module is added to the teaching system to allow students to understand job requirements from the early stage of study.

Post simulation internship is to use the actual work of corporate posts to simulate management and professional training of students, so that students really understand the sweets and bitters of the work process, and master the rules and methods of work from the training. During the entire post simulation internship, students are managed according to the team model, and there are two main training forms.

\section{B. Post Simulation Training Form of Order Acceptance Method}

It is necessary to make orders according to the tourism crafts required by the client, mainly study the distribution of materials and process flow, and train students' craft skills and practical operation ability.

The integration of the post simulation practice module into the professional daily teaching is the focus of this modular teaching mode practice, and its effect needs to be further verified in practice.

\section{FORMULATION OF A MODULAR TALENT TRAINING PROGRAM FOR TOURISM CRAFTS DESIGN MAJORS}

Based on the exploration and innovation of the idea of modular teaching reform, it is necessary to meet the knowledge goals, ability goals and quality goals of the teaching goals, and build a modular teaching system for tourism crafts design specialty. Taking Yanshan Nanshan University as an example, the first and second semesters are mainly public compulsory courses and professional basic course modules. Public courses mainly include English, computer, P.E., etc.; professional basic courses are mainly composed of computer-aided design and design thinking courses, all of which are carried out in a modular manner. Theory and practice are connected and interwoven, with emphasis on cultivating students' design foundation and design thinking. The 3rd to 6th semesters are mainly professional skills modules, interspersed with professional theoretical knowledge modules. The main courses include design modules for cloth, ceramics, lacquer, and metal craft tourism products. The focus is on cultivating students' knowledge and practical skills in different types of crafts, materials, and production processes. The learning methods are as described above; theoretical courses mainly include material courses, design principles, history of arts and crafts, etc., to enrich students' knowledge reserve and lay the foundation for later design practice. The 7th to 8th semester is mainly a post simulation internship module, which allows students to set up project teams, conduct job internship simulation exercises, and complete the graduation design module. Among them, the professional simulation training module is integrated into the post simulation practice module, so that students can truly understand the post requirements and market requirements in practice. 


\section{CONCLUSION}

The entire modular teaching practice training mode is centered on application ability, and the post simulation internship modular teaching mode is integrated into the curriculum setting of the entire training process. It continuously explores and innovates the class form, and provides reference for the teaching of tourism crafts design and related majors.

\section{REFERENCES}

[1] Zhang Cheng, Tao Feng, Ding Na, Yu Guodong. Thoughts on the Modularization of Architecture Specialty in Applicationoriented Universities - Taking Hefei University as an Example [J], Journal of Chifeng University, 2016.03,32 (3) I. (in Chinese)

[2] Qian Shi, Analysis of Teaching Cases in Modular Teaching Mode [D], 2014.04. (in Chinese)

[3] Yang Weiwen, Discussion and Practice of the Modularized Teaching Reform of Segmentation [J], Science and Technology Innovation Herald, 2009 (21). (in Chinese)

[4] Zhang Yuan, Jia Zhongtian, Exploration of Exploration of "Modularization + Interactive" Bilingual Teaching [J], Higher Engineering Education Research, 2008 (1). (in Chinese)

[5] Wu Lijun, Opinions on the Curriculum of Tourism Crafts Specialty [J], Zhejiang Arts and Crafts, 2008.03. (in Chinese) 